\title{
Does the Reprocessing of Endoscopes Have to Take Place Immediately after Pre-Cleaning? A First Evaluation
}

\author{
Vanessa M Eichel', Jonas M Jabs ${ }^{1,3}$, Samy Unser ${ }^{1}$, Nico T Mutters ${ }^{1,3}$ and Martin Scherrer ${ }^{2}$ \\ ${ }^{1}$ Section for Hospital Hygiene and Environmental Health, Center for Infectious Diseases, Heidelberg University Hospital, Im \\ Neuenheimer Feld 324, Heidelberg, ${ }^{2}$ Infection Control Engineering, Center for Infectious Diseases, Heidelberg University Hospital, Im \\ Neuenheimer Feld 324, Heidelberg, ${ }^{3}$ Institute of Hygiene and Public Health, University Hospital Bonn, Venusberg-Campus 1, Bonn, \\ Germany
}

Background/Aims: The recommendations on the time interval between pre-cleaning and reprocessing of endoscopes differ in international guidelines, with a low level of evidence. The aim of this study was to investigate the influence of postponing reprocessing on the reprocessing quality after pre-cleaning the flexible endoscopes.

Methods: We reprocessed 124 standardized test tubes simulating endoscope channels after soiling and contamination and determined the reprocessing performance. In addition, we examined contaminated gastroscopes, colonoscopes, and bronchoscopes. The duration of interim storage after pre-cleaning was $16 \mathrm{~h}$ for 100 test tubes and up to $24 \mathrm{~h}$ for 18 endoscopes. We determined the residual protein content and germ load as markers for cleaning and disinfection performance. In addition, we determined biofilm formation by photometry of crystal violet staining.

Results: All test tubes and flexible endoscopes showed residual protein content and germ load significantly below legally prescribed threshold values, independent of the interval between pre-cleaning and reprocessing.

Conclusions: Our findings indicate that flexible endoscopes could be stored overnight after pre-cleaning without any influence on the quality of reprocessing. While ensuring patient safety, this could simplify logistical processes and enable cost savings. Clin Endosc 2021;54:526-533

Key Words: Biofilm; Endoscope; Pre-cleaning; Reprocessing; Validation

\section{INTRODUCTION}

The professional reprocessing of flexible endoscopes is essential to prevent infection and for patient safety purposes. There have been multiple outbreaks of multidrug-resistant organisms caused by inadequately reprocessed endoscopes. ${ }^{1-3}$ However, special technical knowledge and considerable per-

Received: August 27, 2020 Revised: December 11, 2020

Accepted: January 10, 2021

Correspondence: Martin Scherrer

Infection Control Engineering, Center for Infectious Diseases, Heidelberg University Hospital, Im Neuenheimer Feld 324, Heidelberg 69120, Germany

Tel: +49 6221 56-35959, Fax: +49 6221 56-5627, E-mail: Martin.scherrer@med. uni-heidelberg.de

ORCID: https://orcid.org/0000-0003-1541-3361

(c) This is an Open Access article distributed under the terms of the Creative Commons Attribution Non-Commercial License (http://creativecommons.org/ licenses/by-nc/3.0) which permits unrestricted non-commercial use, distribution, and reproduction in any medium, provided the original work is properly cited. sonnel resources through manual work steps are required to ensure the continuous quality of endoscope reprocessing. ${ }^{4,5}$ In Germany, the joint recommendation of the Commission for Hospital Hygiene and Infection Prevention (KRINKO) and the Federal Institute for Drugs and Medical Devices (BfArM) on the reprocessing criteria of flexible endoscopes and other medical devices is decisive. ${ }^{6}$ It suggests the possibility of interim storage of medical devices during reprocessing. In the case of flexible endoscopes, a pre-cleaning or bedside cleaning process must be carried out immediately after use to remove coarse contaminants such as blood and tissue. The time interval of interim storage is not specified in the German recommendation. Recommendations of other European and Anglo-Saxon countries, including Korea, do not propose an interim storage time after pre-cleaning, ${ }^{7-14}$ or they propose short periods between 30 minutes and 3 hours. ${ }^{15-18}$ The maximum possible time interval may be based on purely theoretical considerations. ${ }^{18-20}$ Empirical studies on the effects of a 
postponement on the reprocessing quality are not available. Due to these vague time frames, practitioners sometimes use single-use endoscopes during weekends or night shifts when centralized reprocessing of regular endoscopes cannot be ensured within $3 \mathrm{~h}$. These endoscopes, however, tend to be inferior in diagnostic purposes than regular endoscopes. In order to ensure consistent patient safety, this study examines the influence of interim storage on the reprocessing quality and evaluates whether time periods longer than $3 \mathrm{~h}$ would allow high quality reprocessing.

\section{MATERIALS AND METHODS}

To examine the reprocessing performance, we used standardized test tubes and real endoscopes that had already been applied to patients. We investigated the effects of the duration of the time interval after pre-cleaning on the reprocessing performance by determining the cleaning performance, disinfection performance, and biofilm content.

\section{Test material}

Based on a previous study, we used 124 test tubes that were produced and validated as test materials. ${ }^{21-23}$ These were transparent polytetrafluoroethylene tubes with a length of $200 \mathrm{~cm}$, an inner diameter of $2 \mathrm{~mm}$, and a wall thickness of $0.5 \mathrm{~mm}$ (HYBETA GmbH; Münster, Germany). In addition, we examined 6 bronchoscopes, 6 gastroscopes, and 6 colonoscopes used clinically for at least 2 years (Olympus Deutschland GmbH; Hamburg, Germany).

\section{Contamination}

To investigate the cleaning performance, the test tubes were contaminated with a soiling solution of heparinized sheep blood and protamine in sodium dodecyl sulfate (SDS) according to method A in accordance with the Guideline for the Validation of Mechanical Cleaning and Disinfection Processes for the reprocessing of thermolabile endoscopes (see Supplementary Material 1 [S1]). ${ }^{24}$ Based on a previous study, we investigated the disinfection performance by introducing a defined quantity of a test organism into the test tubes with the contamination (E. faecium $\geq 10^{9}$ Colony-forming unit (CFU)/ $\mathrm{mL}),{ }^{23}$ aligned with the usual contamination of endoscopes after use, between $>10^{3}$ and $10^{10} \mathrm{CFU} / \mathrm{mL}$ (see S1). ${ }^{25}$ The contaminated test tubes are shown in Fig. 1.

The bronchoscopes, gastroscopes, and colonoscopes were not particularly contaminated since they were contaminated through usage in patients.

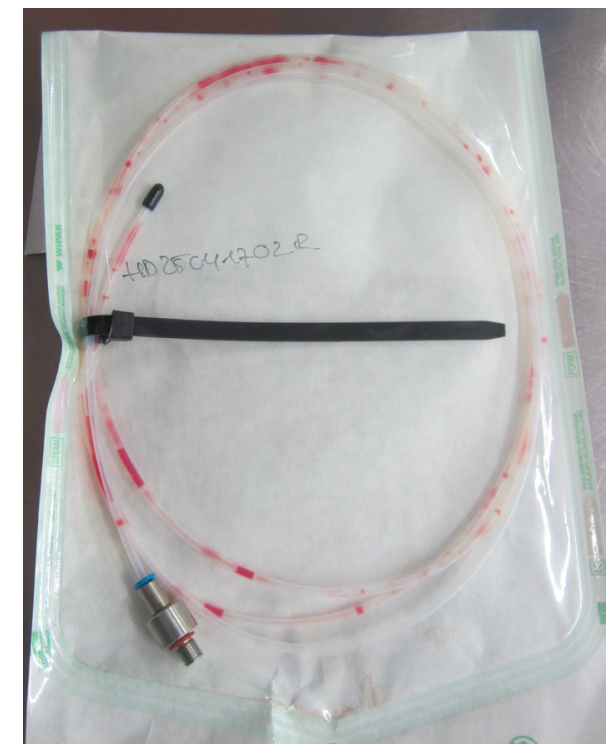

Fig. 1. Test tube after standardized contamination.

\section{Pre-cleaning, storage and reprocessing}

The tubes and endoscopes were prepared according to above-mentioned KRINKO and BfArM recommendations (Tables 1 and 2). ${ }^{6}$ In order to check all reprocessing protocols established in our hospital and to increase the external validity, the tubes were reprocessed at least five times at four locations.

The time interval of storage between pre-cleaning and subsequent reprocessing differed. In 100 cases, a duration of 16 hours was chosen, since it was the most clinically significant time interval if reprocessing takes place daily during core working hours, including weekends. In addition, storage times from 0 to $48 \mathrm{~h}$ were assessed. In endoscopes, the time intervals were 0,6 , and $24 \mathrm{~h}$ after pre-cleaning. The endoscopes were stored at room temperature.

\section{Assessment of cleaning and disinfection performance}

The cleaning and disinfection performance was examined according to the currently valid acceptance criteria in Germany, as they are used to evaluate reprocessing in the context of validation of mechanical cleaning and disinfection processes for reprocessing of thermolabile flexible endoscopes, ${ }^{22-24}$ and according to the KRINKO/BfArM recommendation. ${ }^{6}$ These differ from the International Organization for Standardization (ISO)/Technical Specification (TS) 15883-5 by the reduced bacterial count. ${ }^{21}$ In brief, this entails an optical cleanliness, a residual protein content $\leq 100 \mu \mathrm{g} /$ test tube (cleaning performance), and a reduction factor of $\geq 9 \log _{10} /$ test tube (disinfection performance). For endoscopes, a residual protein content 
$\leq 100 \mu \mathrm{g}$ (cleaning performance) and $<10 \mathrm{CFU} / 10 \mathrm{~mL}$, and no growth of Escherichia coli, Enterobacteriaceae, Enterococci, Pseudomonas aeruginosa, Pseudomonas spp., non-fermenters, and greening streptococci (disinfection performance) were used for acceptance.

Overall, 124 test tubes were reprocessed after the reprocessing protocols specified in Table 1. Subsequently, the test tubes were sent to the laboratory of HYBETA GmbH without further treatment, where the cleaning and disinfection performance was assessed. HYBETA used a bicinchoninic acid assay (BCA assay) to measure protein residues with a minimum detection of $30 \mu \mathrm{g} / \mathrm{test}$ object and $5 \mu \mathrm{g} / \mathrm{endoscope}$ and a maximum validated linear detection ability of up to $250 \mu \mathrm{g}$ protein, according to German standards. ${ }^{6,22,23}$ A 5-point calibration curve from 0 to $200 \mu \mathrm{g} / \mathrm{mL}$ was added to each 96 well plate as a positive control and to ensure precise linear detection. The correlation coefficient of calibration was at least 0.98 .

In total, 18 endoscopes, notably 6 gastroscopes, 6 colonoscopes, and 6 bronchoscopes, were reprocessed after clinical use according to the protocol specified in Table 2. The duration of the time interval between pre-cleaning and subsequent reprocessing varied from $0 \mathrm{~h}$ to $24 \mathrm{~h}$. After reprocessing, samples were taken from the instrument channel and additional irrigation channel and gastroscopes and colonoscopes were taken from the air/water channel, and from the suction channel (see Supplementary Material 2). To investigate the cleaning performance, the respective channel was rinsed four times with the same $10 \mathrm{~mL}$ of $1 \%$ SDS solution. To examine the disinfection performance, the channels were rinsed once with $20 \mathrm{~mL}$ of sterile physiological sodium chloride solution. The samples used to demonstrate the cleaning performance were examined in the laboratory of HYBETA GmbH by BCA assay. The samples assessed for the disinfection were examined in the Laboratory for Technical Hygiene at the Section for Hospital Hygiene and Environmental Health, Center for Infectious Diseases, Heidelberg University Hospital, as detailed in the Supplementary Material 3.

The cleaning and disinfection performance examinations were carried out separately for each endoscope to exclude any influence of the examination on the result.

\section{Investigation of biofilm formation}

Biofilm formation was identified using a validated method proposed by Günther et al. ${ }^{26}$ Therefore, three test tubes were soiled and contaminated as described above and reprocessed according to Table 1 . The process was stopped (i) after pre-cleaning and 24-h storage, which served as a positive control, (ii) after pre-cleaning, 24-h storage, and brush cleaning, or (iii) after pre-cleaning, 24-h storage, and complete reprocessing. Subsequently, the biofilm was measured. An unsoiled test tube was used as a negative control. To investigate biofilm formation, the test tube was rinsed twice with $200 \mu \mathrm{L}$ distilled

Table 1. Protocol of Reprocessing of Test Tubes

Variable time interval of storage at room temperature
Place the test object in the basin with cleaning solution ${ }^{\text {a) }}$
Rinse the test object with cleaning solution ${ }^{\text {a) }}$
Brush the inner lumen with a flexible disposable brush until the brush is free of impurities
Rinse the test object in a basin with demineralised water, rinse the inner lumen
Remove of residual water with medical compressed air
Connect the test object to the loading trolley of the EWD
Dry the test object with medical compressed air
EWD, endoscope washer disinfector.
a) Protocol 1: Hartmann Bodedex forte 2\%; Protocol 2: Hartmann Bodedex forte 1\%; Protocols 3 and 4: Dr. Weigert Neodisher Endo DIS
active.
brotocol 1: Olympus ETD4+GA, Program 2 Standard TR, Hartmann Korsolex Endo Cleaner + Hartmann Korsolex Endo Disinfectant;
Protocol 2: Olympus ETD4+GA (Program 1 Standard) + Hartmann Korsolex Endo Cleaner + Hartmann Korsolex Endo Disinfectan;
Protocol 3: EWD Wassenburg Adaptascope (normal program) + Dr. Weigert Endo Clean + Dr. Weigert Endo Sept GA; Protocol 4: Olym-
pus ETD3+PAA, Program 6 Standard, Olympus EndoDET + Olympus EndoDIS.


Table 2. Protocol of Reprocessing of Broncho-, Gastro- and Colonoscopes

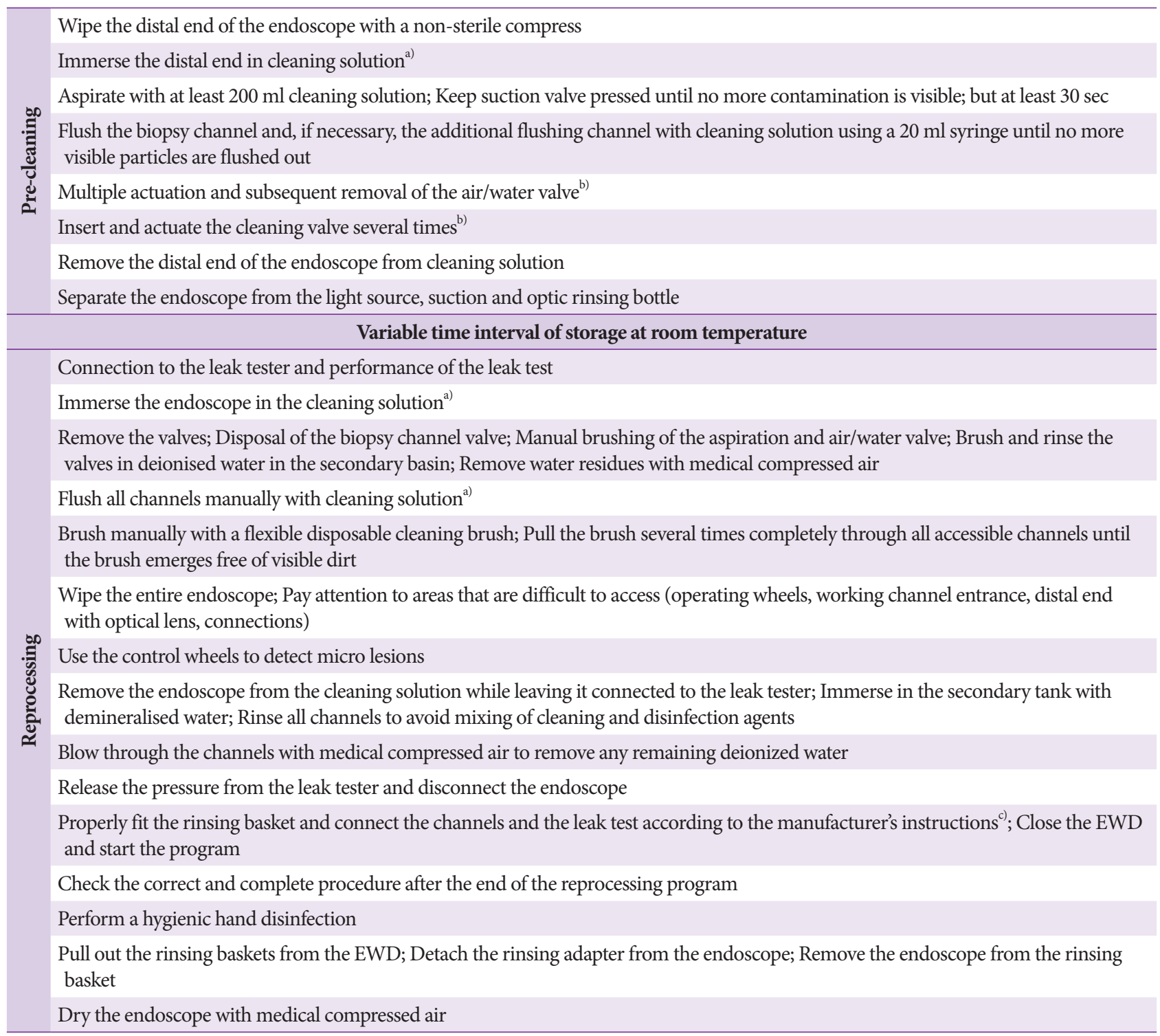

EWD, endoscope washer disinfector.

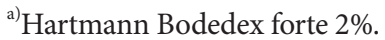

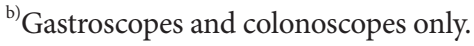

${ }^{c}$ Adapter plate Olympus2 for gastroscopes and colonoscopes; adapter plate Olympus 1 (extension kit BF) for bronchoscopes.

water. The biofilm was stained by adding $150 \mu \mathrm{l}$ of $0.1 \%$ crystal violet solution and stored for $20 \mathrm{~min}$ at room temperature. Afterwards, the test tubes were rinsed twice with $200 \mu \mathrm{l}$ distilled water to remove excess crystal violet. Finally, the crystal violet dye bound in the biofilm was washed out by adding $150 \mu \mathrm{L}$ of $10 \%$ ethanol. We determined the quantity of bound crystal violet in each test tube as a surrogate marker for the still existing biofilm mass six times by photometric absorption measurement at a wavelength of $570 \mathrm{~nm}$.

\section{RESULTS}

\section{Test tubes}

In total, 124 soiled and soiled/contaminated test tubes were reprocessed after interim storage for $0-48 \mathrm{~h}$ after pre-cleaning (Fig. 2). All test tubes were optically clean regardless of the time interval and had a residual protein content of $<30 \mu \mathrm{g} /$ test tube (detection minimum). A reduction factor $\geq 9 \log _{10} /$ test tube was determined for the number of CFUs of E. faecium 


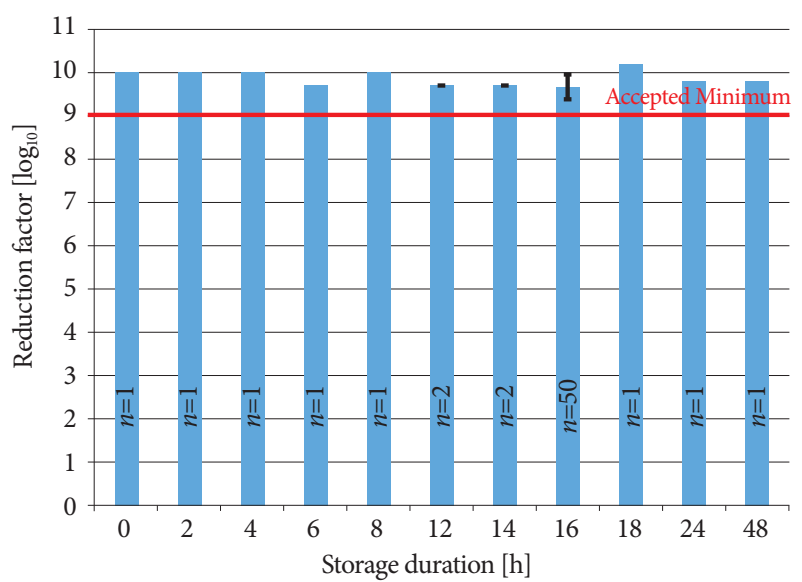

Fig. 2. Disinfection performance of the test tubes as a function of storage duration after pre-cleaning. Reduction factor of $E$. faecium $\mathrm{CFU} / \mathrm{ml}$ after processing. Bars indicate standard deviation. CFU, colony-forming unit.

(Fig. 2). Thus, the cleaning and disinfection performance at extended storage intervals after pre-cleaning met the acceptance criteria.

\section{Endoscopes}

To increase the transferability to the clinical setting and account for differences in design and for the effects of material wear such as roughening in the canal lumen, the cleaning and disinfection performance was repeated on endoscopes used for at least 2 years. After usage, the 6 bronchoscopes, 6 gastroscopes and 6 colonoscopes were reprocessed and stored for up to $24 \mathrm{~h}$ after pre-cleaning. No endoscope was contaminated with a protein residue above the detection limit of $5 \mu \mathrm{g} / \mathrm{endo}-$ scope. Therefore, the acceptance criterion of a protein residue of $\leq 100 \mu \mathrm{g}$ was met in all the collected samples. Furthermore, we noted a colony count $<10 \mathrm{CFU} / 10 \mathrm{~mL}$ (Fig. 3) and no growth of Escherichia coli, Enterobacteriaceae, Enterococci, Pseudomonas aeruginosa, Pseudomonas spp., non-fermenters, and greening streptococci. Thus, the acceptance criteria for both cleaning performance and disinfection performance were met.

\section{Biofilm formation}

We investigated biofilms formation at several points in the reprocessing protocol (Fig. 4). While biofilm was detected after pre-cleaning and 24-h storage, the optical density (OD) after pre-cleaning, storage, and brush cleaning, and after complete reprocessing with storage was similar to that of the uncontaminated control.

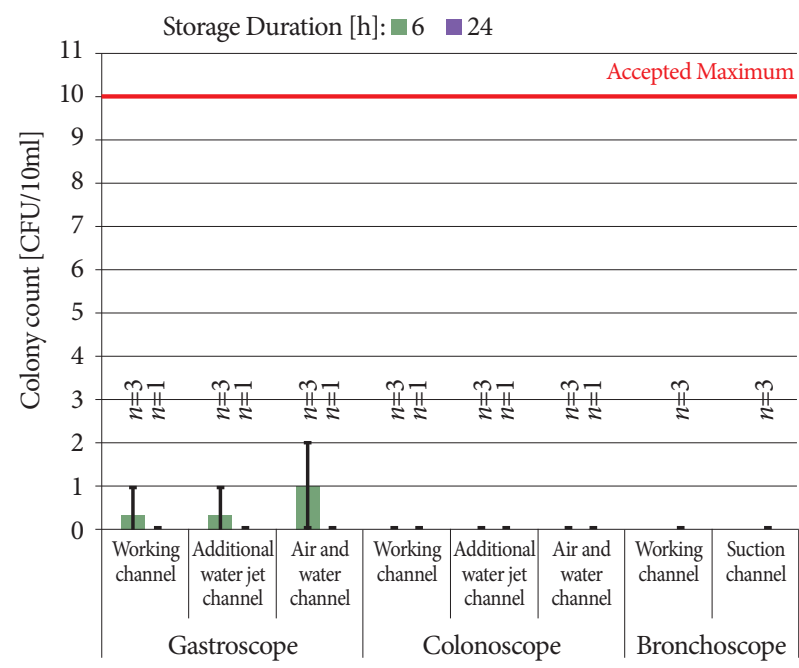

Fig. 3. Disinfection performance of endoscopes as a function of storage duration after pre-cleaning. CFU/10 ml after reprocessing. Bars indicate standard deviation. CFU, colony-forming unit.

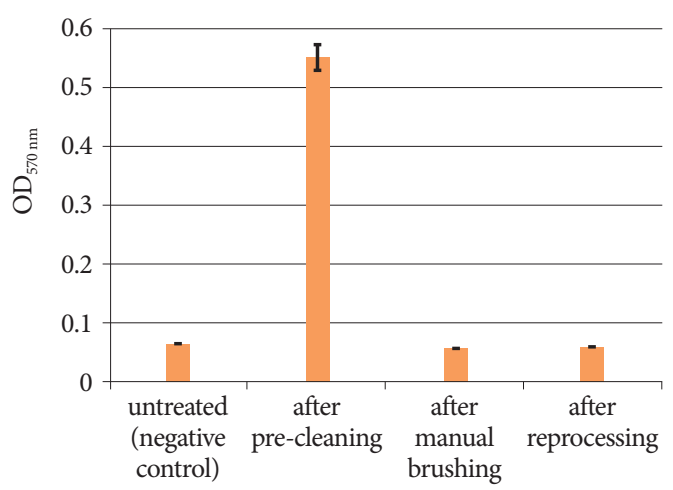

Fig. 4. Photometric investigation of biofilm formation in the treatment process. Three test tubes were soiled and contaminated with Enterococcus faecium. During the preparation according to protocol 1 , they were stored for $24 \mathrm{~h}$ after pre-cleaning. One test tube that was not soiled served as negative control. As a marker for biofilms, an optical density (OD) of $570 \mathrm{~nm}$ after staining with crystal violet was determined $6 \times$ per test tube. Bars indicate standard deviation.

\section{DISCUSSION}

To our knowledge, this is the first study to examine the influence of prolonged storage time periods of flexible endoscopes after pre-cleaning on reprocessing quality. We examined the storage durations for up to $48 \mathrm{~h}$ in 124 test tubes and up to $24 \mathrm{~h}$ in 18 bronchoscopes, gastroscopes and colonoscopes. The cleaning and disinfection performance was orientated according to the German legislation and guidelines $^{6-24}$ and ISO/TS 15883-5 from 2005. ${ }^{21}$ This differed from the European norms by the more stringent acceptance criteria 
(lower threshold values for non-acceptance) and an additional patency test. All endoscopes and test tubes met the quality criteria for reprocessing, even after longer storage time periods.

We also used validated single-use test tubes to increase the size of the repetitions. The highest number of repetitions $(n=50)$ was chosen for the 16-h interval, as this is probably the maximum storage period assuming reprocessing was carried out only during core working hours, including weekends.

As described at the beginning, the relevant period was not defined by official bodies in Germany. ${ }^{24}$ The US-American Multisociety Guideline recommends cleaning and drying after pre-cleaning. ${ }^{8}$ The Dutch Steering group for flexible endoscope cleaning and disinfection and the French Ministère des Affaires Sociales et de la Santé state that manual cleaning should take place immediately after pre-cleaning. ${ }^{10,11}$ Similarly, the Swiss guidelines for reprocessing flexible endoscopes and the Australian Infection Control Guidelines of the Gastroenterological Society of Australia and the Australian Gastrointestinal Endoscopy Association require immediate pre-cleaning and manual cleaning after use. ${ }^{12,17}$ This is referred to in the international paper of the European Society of Gastrointestinal Endoscopy and the European Society of Gastroenterology Nurses and Associates, which justifies the formulation of a maximum time interval of one hour with theoretical considerations on the population kinetics of microorganisms and the fixation of proteins by drying. ${ }^{19,20}$ Specifically, it is assumed that the shorter doubling time of gram-negative bacteria of a minimum of 20-30 min allows the formation of biofilms if the entire treatment process is not carried out in a timely manner. This consideration does not consider the validity of this information for optimal growth conditions in vitro, that pre-cleaning directly after the patient examination can reduce contamination, and that an emerging biofilm can possibly be removed during reprocessing. Our experiment on biofilm formation suggests that biofilm can be formed during storage after pre-cleaning, but that it can be removed by brushing afterwards. This procedure of visualizing and quantifying cells adhering to the tube wall by crystal violet solution has been described by O'Toole and Kolter. ${ }^{27}$ Biofilm production can be assumed if the OD is greater than the mean value of the negative control, added thrice to its standard deviation. ${ }^{28}$ Although Stepanovic et al. ${ }^{28}$ tested the biofilm of Staphylococci on microtiter plates, the basic consideration that justifies the above formula is justified and plausible; this is that biofilm production is subject to a variety of methodological influences.

Our study has some limitations. The number of repetitions is still too low to conclude sufficient preparation quality, especially for storage times other than $16 \mathrm{~h}$. Therefore, we encourage researchers, especially those with different method- ologies, to repeat the assay. Other flexible endoscopes were not assessed due to their critical reprocessing procedures (e.g. duodenoscopes) or because they are usually single-use products (e.g. ureteroscopes).

The recommended methods used to validate reprocessing for flexible endoscopes differ from country to country. For example, in contrast to the German/European norms, the US Food and Drug Administration (FDA) recommends the thresholds for an acceptable level of contamination of $<6.4$ $\mu \mathrm{g} / \mathrm{cm}^{2}$ protein, $<2.2 \mu \mathrm{g} / \mathrm{cm}^{2}$ hemoglobin, and $<1.8 \mu \mathrm{g} / \mathrm{cm}^{2}$ carbohydrate. ${ }^{29,30}$ Furthermore, the techniques of sampling strategy differ (brushing or simple flushing), volume, and used substances (saline, demineralized water, neutralizer). ${ }^{31,32}$ In addition, the contents of the test soil are discussed internationally. Some authors do not recommend heparin for the validation of flexible endoscope reprocessing, as it may inhibit some bacterial strains from adhering and from forming biofilms. They recommend using coagulated blood as test soil or preferably ATS2015 and Edinburgh-M soils. ${ }^{33,34}$ The European Committee for Standardization informatively recently suggests the contamination of flexible endoscopes with biofilm-producing Pseudomonas aeruginosa for the examination of cleaning performance of washer disinfectors. ${ }^{35}$ Therefore, it would be interesting to reevaluate our results by employing the newly suggested contamination method or international methods of contamination, sampling, and evaluation.

In summary, our findings may indicate that flexible endoscopes can be stored after pre-cleaning for up to $16 \mathrm{~h}$ without any influence on the reprocessing quality according to current test standards. We propose to evaluate international protocols and acceptance criteria for the reprocessing of flexible endoscopes also for longer storage periods if pre-cleaning is ensured. This would presumably reduce the use of single-use endoscopes, which would increase diagnostic quality and enable cost-savings.

Conflicts of Interest

The authors have no potential conflicts of interest.

Funding

None.

Acknowledgments

We thank the staff of the interdisciplinary endoscopy center, the sterility supply departments of the orthopedic ward, the children's clinic, and the head clinic of the Heidelberg University Hospital for most of the practical implementation and for their willingness to adapt the procedures to the needs of our study. We also thank Olympus Deutschland GmbH for the provision of loaner endoscopes and the companies Hybeta GmbH and Karl Storz SE \& Co. KG. 


\author{
Authors Contributions \\ Conceptualization: Martin Scherrer \\ Data curation: Vanessa M Eichel, MS \\ Formal analysis: VME, MS \\ Investigation: VME, MS \\ Methodology: VME, MS \\ Project administration: Samy Unser \\ Resources: Jonas M Jabs, SU \\ Supervision: Nico T Mutters, MS \\ Validation: NTM, MS \\ Visualization: VME, JMJ, SU, MS \\ Writing-original draft: VME \\ Writing-review\&editing: NTM
}

\section{ORCID}

Vanessa Maria Eichel:

Jonas Matthias Jabs:

Samy Unser:

Nico Tom Mutters:

Martin Scherrer:

\begin{abstract}
https://orcid.org/0000-0003-3259-2920 https://orcid.org/0000-0002-3034-3237 https://orcid.org/0000-0001-8613-0655 https://orcid.org/0000-0002-0156-9595 https://orcid.org/0000-0003-1541-3361
\end{abstract}

\section{REFERENCES}

1. Kumarage J, Khonyongwa K, Khan A, Desai N, Hoffman P, Taori SK. Transmission of multi-drug resistant Pseudomonas aeruginosa between two flexible ureteroscopes and an outbreak of urinary tract infection: the fragility of endoscope decontamination. J Hosp Infect 2019;102:89-94.

2. Naas T, Cuzon G, Babics A, et al. Endoscopy-associated transmission of carbapenem-resistant Klebsiella pneumoniae producing KPC-2 beta-lactamase. J Antimicrob Chemother 2010;65:1305-1306.

3. Shimono N, Takuma T, Tsuchimochi N, et al. An outbreak of Pseudomonas aeruginosa infections following thoracic surgeries occurring via the contamination of bronchoscopes and an automatic endoscope reprocessor. J Infect Chemother 2008;14:418-423.

4. McCafferty CE, Aghajani MJ, Abi-Hanna D, Gosbell IB, Jensen SO. An update on gastrointestinal endoscopy-associated infections and their contributing factors. Ann Clin Microbiol Antimicrob 2018;17:36.

5. Shellnutt C. Advances in endoscope reprocessing technology and its impact on pathogen transmission. Gastroenterol Nurs 2016;39:457-465.

6. Anforderungen an die Hygiene bei der Aufbereitung von Medizinprodukten. Bundesgesundheitsbl 2012;55:1244-1310.

7. Canada PHA of. Infection prevention and control guideline for flexible gastrointestinal endoscopy and flexible bronchoscopy [Internet]. Ottawa: Public Health Agency of Canada; c2011 [updated 2011 Feb 10; cited 2021 May 31]. Available from: https://www.canada.ca/en/public-health/ services/infectious-diseases/nosocomial-occupational-infections/infection-prevention-control-guideline-flexible-gastrointestinal-endoscopy-flexible-bronchoscopy

8. Reprocessing Guideline Task Force, Petersen BT, Cohen J, et al. Multisociety guideline on reprocessing flexible GI endoscopes: 2016 update. Gastrointest Endosc 2017;85:282-294.e1.

9. Alvarado CJ, Reichelderfer M. APIC guideline for infection prevention and control in flexible endoscopy. Association for professionals in infection control. Am J Infect Control 2000;28:138-155.

10. Guide Technique - Traitement des endoscopes souples thermosensibles à canaux [Internet]. Paris: Ministère des affaires sociales et de la santé en France; c2019 [updated 2019 Aug 6; cited 2021 May 31]. Available from: https://solidarites-sante.gouv.fr/IMG/pdf/dgos_traitement_endoscopes. pdf

11. Professional Standard Handbook Cleaning and Disinfection Flexible Endoscopes Version 4.1 [Internet]. Netherlands: SFERD; c2017 [updated
2017 Sep; cited 2021 May 31]. Available from: https://www.infectiepreventieopleidingen.nl/downloads/SFERDHandbook4_1.pdf

12. Schweizerische Richtlinie zur Aufbereitung flexibler Endoskope [Internet]. Bern: Schweizerische Gesellschaft für Gastroenterologie (SGG); c2010 [cited 2021 May 31]. Available from: https://sggssg.ch/fileadmin/_ migrated/content_uploads/Arzt_17_Schweizerische_Hygienerichtlinie. pdf.

13. Richtlinien und Empfehlungen :: SVEP-ASPE [Internet]. [cited 2021 May 31]. Available from: https://svep-aspe.ch/fileadmin/user_upload/ pdf/CH_Richtlinie_ESGE_2020_07_10.pdf

14. Son BK, Kim B-W, Kim WH, et al. Korean society of gastrointestinal endoscopy guidelines for endoscope reprocessing. Clin Endosc 2017;50:143-147.

15. Health Technical Memorandum 01-06: Decontamination of flexible endoscopes [Internet]. London: Department of Health \& Social Care UK; c2016 [cited 2021 May 31]. Available from: https://assets.publishing. service.gov.uk/government/uploads/system/uploads/attachment_data/ file/530418/HTM0106_PartA.pdf; 2016

16. 2020 Guidance on Decontamination of Equipment for Gastrointestinal Endoscopy [Internet]. London: The British Society of Gastroenterology; c2020 [cited 2021 May 31]. Available from: https://www.bsg.org.uk/ clinical-resource/guidance-on-decontamination-of-equipment-for-gastrointestinal-endoscopy/.

17. Infection control in Endoscopy [Internet]. Wales: Gastroenterological Society of Australia and Gastroenterological Nurses College of Australia; c2011 [cited 2021 June 21]. Available from: https://www.genca.org/public/5/files/Endoscopy_infection_control\%20(low).pdf

18. Beilenhoff $U$, Biering H, Blum R, et al. Reprocessing of flexible endoscopes and endoscopic accessories used in gastrointestinal endoscopy: position statement of the European Society of Gastrointestinal Endoscopy (ESGE) and European Society of Gastroenterology Nurses and Associates (ESGENA) - update 2018. Endoscopy 2018;50:1205-1234.

19. Beilenhoff U. Welches Zeitfenster ist für die Aufbereitung zu empfehlen? Dürfen Endoskope länger oder gar über Nacht liegen bleiben? Wie ist bei infektiösen Patienten zu verfahren? Endo-Praxis 2018;34:116-120.

20. Beilenhoff $\mathrm{U}$, Biering $\mathrm{H}$, Blum R, et al. Prevention of multidrug-resistant infections from contaminated duodenoscopes: position statement of the European Society of Gastrointestinal Endoscopy (ESGE) and European Society of Gastroenterology Nurses and Associates (ESGENA). Endoscopy 2017;49:1098-1106.

21. ISO/TS 15883-5:2005 Washer-disinfectors - Part 5: Test soils and methods for demonstrating cleaning efficacy [Internet]. Geneva: ISO; c2005 [cited 2021 May 31]. Available from: https://www.iso.org/cms/render/ live/en/sites/isoorg/contents/data/standard/04/11/41175.html.

22. Wehrl M, Kircheis U. Methods for testing the cleaning performance of washing-disinfection equipment for flexible endoscopes. 2011;36:402406.

23. Kircheis $U$, Wehrl M. Method for testing the cleaning and disinfecting efficacy of washer-disinfectors for flexible endoscopes. Zentralsterilisation - Central Service 2012;20:240-249.

24. Guideline of DGKH, DGSV and AKI for the validation and routine monitoring of automated cleaning and thermal disinfection processes for medical devices [Internet]. Wiesbaden: Zentral STERILISATION; c2017 [cited 2021 June 21]. Available from: https://shop.mhp-verlag.de/ media/pdf/6b/d0/17/MHP_ZS-Supplement-ENG-2017_E-Paper59e49ae0660bc.pdf

25. Kampf G, Fliss PM, Martiny H. Is peracetic acid suitable for the cleaning step of reprocessing flexible endoscopes? World J Gastrointest Endosc 2014;6:390-406.

26. Günther F, Scherrer M, Kaiser SJ, DeRosa A, Mutters NT. Comparative testing of disinfectant efficacy on planktonic bacteria and bacterial biofilms using a new assay based on kinetic analysis of metabolic activity. J Appl Microbiol 2017;122:625-633.

27. O’Toole GA, Kolter R. Initiation of biofilm formation in Pseudomonas 
fluorescens WCS365 proceeds via multiple, convergent signalling pathways: a genetic analysis. Mol Microbiol 1998;28:449-461.

28. Stepanović S, Vuković D, Hola V, et al. Quantification of biofilm in microtiter plates: overview of testing conditions and practical recommendations for assessment of biofilm production by staphylococci. APMIS 2007;115:891-899.

29. Alfa MJ, Degagne P, Olson N. Worst-case soiling levels for patient-used flexible endoscopes before and after cleaning. Am J Infect Control 1999;27:392-401.

30. Alfa MJ. Medical instrument reprocessing: current issues with cleaning and cleaning monitoring. Am J Infect Control 2019;47S:A10-A16.

31. Cattoir L, Vanzieleghem T, Florin L, et al. Surveillance of endoscopes: comparison of different sampling techniques. Infect Control Hosp Epidemiol 2017;38:1062-1069.
32. Shin SP, Kim WH. Recent update on microbiological monitoring of gastrointestinal endoscopes after high-level disinfection. Clin Endosc 2015;48:369-373.

33. Alfa MJ, Olson N. Physical and composition characteristics of clinical secretions compared with test soils used for validation of flexible endoscope cleaning. J Hosp Infect 2016;93:83-88.

34. Chen X, Ling P, Duan R, Zhang T. Effects of heparosan and heparin on the adhesion and biofilm formation of several bacteria in vitro. Carbohydrate Polymers 2012;88:1288-1292.

35. ISO 15883-5 Washer-disinfectors - Part 5: Performance requirements and test method criteria for demonstrating cleaning efficacy [Internet]. Geneva: ISO; c2021 [cited 2021 May 31]. Available from: https://www. iso.org/standard/68297.html 